\title{
A CONSTRUÇÃO, A DESTRUIÇÃO E A RECONSTRUÇÃO DO ESPAÇO URBANO NA CIDADE DE PORTO ALEGRE DO INICIO DO SÉCULO XX
}

\author{
Vanda Ueda*
}

\section{RESUMO:}

No início do século $X X$ a cidade de Porto Alegre passava por grandes transformações, e sua reestruturação deu-se através da implantação das redes técnicas e de um novo sistema viário, que eram utilizados como um meio de modernização. A cidade deveria tornar-se um espaço habitável e higiênico, além de ser capaz de absorver todas as inovações técnicas disponíbeis em outras cidades e países. A construção, a destruição e a reconstrução do espaço urbano na cidade atendiam aos desejos da burguesia e das elites locais, capazes de consumir todas as modernidades existentes.

\section{PALAVRAS-CHAVE:}

Espaço urbano, geografia histórica, transformações urbanas, modernidade, Porto Alegre.

\section{ABSTRACT:}

In the early $20^{\text {th }}$ Century the city of Porto Alegre (Brazil) pass over great transformations, where the urban restructuring through the implantation of technical networks and a new transport system was utilized like a way of modernization. The city should to be transformed in a habitable and hygienic space, moreover be able to assimilate all the modernities established in other cities and countries. The construction, destruction and the reconstruction of the urban space of the city seeks to pay attention the desires of the bourgeoisie and local elites who was able to consume all existent modernities.

\section{KEY WORDS:}

urban space, historical geography, urban changes, modernity, Porto Alegre (Brazil)

As transformações urbanas em Porto Alegre ocorreram graças aos projetos de modernização implementados no final do século XIX e início do século $X X$, período de grandes mudanças econômicas, políticas e sociais. Para entender-se como se produziram as mudanças no espaço urbano e o momento histórico em que vivia a cidade, pareceu-nos necessário trabalhar com a geografia histórica, vinculando o espaço e o tempo às condições econômicas, políticas, sociais e territoriais. Sabemos que a reconstrução da história ou das histórias urbanas é complexa, mas é necessária e fundamental para que se possa compreender como foram implantados os projetos modernizadores e saber quais os fatores e agentes sociais que atuaram nas transformações urbanas da cidade. Portanto, analisar o processo de urbanização de Porto Alegre é entender a sociedade e a cidade no seu contexto histórico.

A cidade tornou-se um lugar de mudança. Não somente como receptora das modernidades, mas como um produto das novas formas de sociabilidade, permitindo, assim, que os agentes econômicos e políticos pudessem reestruturá-las de acordo com seus interesses. Concordamos com Pesavento (1994) quando a mesma diz que: "a cidade de hoje encerra, pois, 
muitas cidades passadas e vividas que, se não é possível resgatá-las na sua integridade, busca-se pelo menos decifrar as suas representações (...) as representações sociais, são, por assim dizer, históricas, concebidas em cruzamentos com práticas historicamente determinadas".

Nesta direção, o artigo analisa as transformações urbanas produzidas em Porto Alegre no final do século XIX e início do século $X X$, levando em consideração os projetos modernizantes e as questões morais de ordem e progresso que estavam presentes nos inúmeros discursos. As reestruturações urbanas, através da implantação das redes técnicas e viárias, eram utilizadas como um meio de modernização, uma vez que a cidade deveria tornar-se um espaço habitável e higiênico, além de ser capaz de absorver todas as modernidades vigentes em outras cidades e países. Dividimos o artigo em duas partes, que se complementam ao final: a primeira contextualiza a cidade de Porto Alegre e analisa a importânica da rua, e a segunda discute as transformações urbanas, a partir da construção de duas grandes avenidas, evidenciando a atuação de vários agentes neste projeto modernizador.

\section{A cidade de Porto Alegre}

A cidade de Porto Alegre tornou-se um local de mudanças e de transformações urbanas. Com o aumento da população, os progressos técnicos, a implantação das inovações tecnológicas e os avanços médicos e sanitários, em um curto período de tempo, multiplica-se o número de habitantes da cidade de Porto Alegre e dos principais centros urbanos do país. Porto Alegre que, no início do século XX tinha 73.674 habitantes passando em 1920 a ter mais de 205.000 habitantes. Este aumento fdeu-se em decorrência das correntes migratórias e da mobilidade da população que alteraram as relações existentes entre as cidades e o campo. Outro fator de aumento da população foi a entrada de capitais estrangeiros e as sucessivas inovações técnicas implementadas na cidade, estas, por sua vez, alterando a paisagem urbana de Porto Alegre.

Gilberto Velho (1999), em seu texto sobre a modernidade urbana, caracteriza este período em que foram implantadas as redes técnicas nas principais cidades brasileiras e do mundo como um processo de globalização, pois houve o estabelecimento de vínculos econômicos, políticos e culturais entre quase todas as regiões do planeta, e as correntes migratórias proporcionaram que os capitais de diversos países se expandissem para vários lugares da geografia mundial. Acrescentamos que as correntes migratórias ocorridas no final do século $X I X$ e as do início do século $X X$ trouxeram para a cidade muitos "imigrantes burgueses" capazes de gerar uma economia forte e inovadora, uma vez que vinham com capitais suficientes para montar seu próprio negócio.

Porto Alegre, que na virada do século tinha uma população de descendência estrangeira, passa a ser o centro das operações comerciais e financeiras. Seu dinamismo econômico esteve, em um primeiro momento, baseado nas atividades comerciais, estas relacionadas com os produtos coloniais e, posteriormente, com a expansão industrial. Convém destacar que, enquanto as cidades de Pelotas e de Rio Grande tinham sua economia baseada na indústria do charque, os industriais de Porto Alegre diversificavam sua produção (SINGER, 1977).

O centro urbano seguia os antigos caminhos de povoamento, que se estendiam rumo aos Campos da Redenção (atual Bom Fim), o Areal da Baronesa (Cidade Baixa), Floresta e Navegantes. Estes espaços, terrenos baldios ou antigos povoados, foram, pouco a pouco sendo absorvidos pela trama urbana e sofrendo um processo de valorização, uma vez que passa-se a construir, ainda que incipientemente, algumas infra-estruturas. As classes médias e os comerciantes (principalmente os imigrantes) começam a ter suas residências e seus 
estabelecimentos nessas áreas (MONTEIRO, 1995, p.34).

A cidade, que se caracterizava por uma intensa ocupação na área da península central, agora se expandia para os bairros mais afastados, e, conseqüentemente, impunha-se a necessidade de dotá-la com todas as infraestruturas. As reformas urbanas atendiam à nova concepção que a elite porto-alegrense tinha de cidade, onde o centro deveria ser um lugar de conduta "civilizada". Palavras como ordenar, intervir no espaço, pautar a conduta dos indivíduos, compor códigos de posturas municipais, construir, destruir e (re)construir edifícios, abrir avenidas, extinguir os becos, entre tantas outras, foram encontradas nos discursos proferidos pelos intendentes municipais.

Novos símbolos de modernidade começaram a implantar-se na cidade e a elite local podia contemplá-los e usufruí-los de acordo com seus interesses e necessidades. Anteriormente a 1900, foram implantados na cidade uma série de benefícios relacionados aos serviços públicos, entre eles: a construção do gasômetro (1874), a regularização da coleta do lixo (1876), a construção do saneamento básico (1878), além da implantação de linhas dos bondes de tração animal (1874) e de linhas telefônicas em 1886 (UEDA, 2001). Esses novos símbolos de modernidade levavam as elites a sentir-se como se estivessem num grande centro urbano e, sempre que possível a comparar as implantações das redes técnicas e as transformações do espaço urbano com as de outras cidades mundiais, como Paris e Londres. Ter todas as modernidades significava, no imaginário da elite, ser "culto e civilizado", conforme documento enviado por Luis Augusto Ferrerira de Almeida ao presidente da Câmara Municipal de Porto Alegre, em 1884, quando o mesmo tentava implantar o serviço telefônico na cidade. Este dizia o seguinte: "o telefone para a vida das pessoas cultas e civilizadas é tão útil e necessário como o telégrafo .(...) Sabemos que Europa e as províncias mais civilizadas e opulentas do Império possuem tão importante melhora, digna de ser utilizada nesta nobre e rica cidade, que destaca por sua natural grandeza" (UEDA, 2002).

No início do século $X X$ a cidade já estava dotada de iluminação elétrica, eletrifica-se o sistema de bondes e muitas oportunidades culturais se ofereciam à elite porto-alegrense. Aparecem novos espaços urbanos e novos lugares de reuniões e de consumo. Surgem as grandes casas comerciais, os cafés (Colombo e América), as confeitarias (Rocco e a Central), os passeios pelas ruas comerciais, os teatros, os lugares de bailes, os lugares de reuniões como o Clube do Comércio e o Grande Hotel, entre outros.

As novas formas de sociabilidade foram aparecendo e ocupando lugar na cena urbana, sobretudo na área central, que foi alvo principal da política de remodelação do espaço urbano (MONTEIRO, 1995). Além desses novos espaços de reuniões e de consumo, a rua passou a ser um ponto de referência no cotidiano das elites.

\section{A rua: microcosmos da modernidade}

A rua, segundo Lefebvre (1971, p.94), se repete e muda como a cotidianidade. Ela representa, na nossa sociedade, a vida cotidiana - os lugares de trabalho, de residência, os lugares de distração. Ela é mais que um lugar de passo, de interferências, de circulação e de comunicação. É, pois, tudo, ou quase tudo: o microcosmo da modernidade.

Do ponto de vista social, na rua podemos encontrar todo tipo de gente e de classe, nela se mesclam as diferentes classes e estratos sociais. Do ponto de vista econômico, a rua pode se converter em um diferenciador social - de frustração e privação uma vez que nem sempre podemos consumir tudo que se oferece nela. Do ponto de vista territorial e de territorialidade, a rua oferece inúmeros diferenciais e podemos encontrar diferentes grupos étnicos, com diferentes culturas que se reúnem para falar de seu povoado, recordar seu passado, etc. É na rua que se encontra, também, diferentes tipos de 
comércio, cuja mirada tornam-se objetos de desejo. Lefebvre (1971, p.96) assinala que, atrás de uma vitrine, os objetos vivem sua vida soberana. Ali esperam a plenitude de sua existência, como mercadorias e valores de câmbio, em seu trajeto entre a produção e o consumo.

Por sua vez, Gourdon (1999) analisa a rua como um espaço multifuncional, pois está associada a um movimento que revela a articulação entre o público e o privado, onde o habitar, trabalhar e circular estão presentes. Assinala, ainda, que uma rua pode mudar de função e de uso, podendo, de acordo com o tempo, passar de rua residencial para rua comercial.

As principais ruas da cidade de Porto Alegre, neste período eram, a Rua da Praia, a 7 de Setembro, a Voluntários da Pátria e a General Câmara, entre outras. Estas ruas simbolizavam e demonstravam em seus edifícios toda a pujança econômica e financeira da elite local. As contradições sociais evidenciavam-se, também, através do comércio local, onde a Rua da Praia, por exemplo, ostentava as lojas de alta costura entre as lojas mas populares. Neste sentido, Bertrand (1981, p.179) assinala que o poder de compra e os desejos evolucionam segundo as modas e a conjuntura, e caracterizam as classes sociais cuja distribuição geográfica serve de base para o serviço comercial.

Em seu livro sobre Porto Alegre, Fortini (1966, p.24) dizia que na Rua da Praia concentrava-se o grosso do comércio retalhista da cidade. E era constante o seu movimento devido à concentração de lojas populares, e as mais procuradas eram: a "Preço Fixo", a Masson, a Esteves Barbosa, a José Gertum, a Levy Leão, Ao Cromômetro de Alberto Felauer, Luiz Velecker (Varejo Bromberg) e Ao Cilindro. Por sua longa extensão, na Rua da Praia também situavamse os principais cafés e confeitarias da cidade, sendo os principais o Café América e o Colombo. O café, segundo Lefebvre (1971, p.97), é um lugar de encontros levados até a promiscuidade, lugar de fantasia enxertada na vida cotidiana, é também o lugar do jogo e do destino pelo destino. É nos cafés que intelectuais, políticos e empresários discutem o rumo da cidade. Nesse vai-e-vem de pessoas, o cotidiano portoalegrense forneceu elementos para muitos escritores e intelectuais, além de diminuir as questões referentes ao gênero.

Na Rua da Praia, além das casas que vendiam artigos populares, existiam também as casas de alta costura, as chamadas "casas de moda", onde homens e mulheres podiam caminhar livremente olhando e desejando todos os objetos disponíveis nas vitrines. As pessoas das classes mais abastadas, podiam não somente contemplar os produtos, mas, também, consumi-los. A rua passou a ser símbolo de modernidade, principalmente para as mulheres, uma vez que a cotidianidade pesava, e com todo peso, sobre cada mulher. Elas experimentaram o mais cargante, agobiante, gris e reiterativo da vida cotidiana, e ir, caminhar e sentir as sensações de "ver e ser vista" na rua foi como um sonho desperto na prática cotidiana (LEFEBVRE, 1971, p.99).

Outra rua importante na configuração urbana de Porto Alegre foi a Voluntários da Pátria, que tinha um intenso tráfego uma vez que servia de conexão entre as indústrias localizadas longe do núcleo central, com os depósitos comerciais situados próximos ao porto da cidade. Segundo Franco (1998) a construção da estação da estrada-de-ferro que ligava Porto Alegre a São Leopoldo deu um novo dinamismo a esta rua, onde começaram a ser construídos alguns edifícios em estilo neoclássico. Construiram-se, também, muitos depósitos industriais, assim como indústrias vinculadas ao setor naval e escritórios das casas comerciais que trabalhavam com importação e exportação de produtos manufaturados.

Com a circulação de riquezas por parte da elite local, decorrente da industrialização, assegurou-se o crescimento da função comercial e bancária da cidade, e, algumas ruas foram se especializando. A Rua 7 de Setembro era um 
exemplo, e simbolizou toda a pujança comercial e financeira da cidade. Alí localizavam-se inúmeras sedes administrativas dos bancos, como a do Banco da Província situada na esquina com a Rua General Câmara. O Banco da Província foi o primeiro banco gaúcho, instalado a 1 de julho de 1856. Inicialmente, o edifício do Banco da Província estava localizado na Rua da Praia, e, em 1885, transfere-se para essa rua. Outro banco situado nesta rua foi o Banco Nacional do Comércio, fundado em 1895, cujos incorporadores estavam vinculados à atividade comercial e industrial. Nos primeiros anos de sua existência o Banco não possuía sede própria, e somente em 1913 optou-se por comprar um sólido edifício nesta rua para a sua matriz. Outros bancos como o Porto-Alegrense (fundado em 1905), o London Bank (instalado em 1888), o National City Bank of New York (instalado em 1812), cujo edifício estava na esquina com a rua 15 de Novembro (LANGEMANN, 1985). Os edifícios eram suntuosos, bem preservados e mostravam todo o potencial econômico e financeiro da cidade.

Além das sedes bancárias, localizavamse nesta rua as principais e mais refinadas casas comerciais, pertencentes, em sua maioria, aos comerciantes de origem imigrante, como: Bromberg, Nickele, Franco, Ramos \& Cia, Bier \& Ullmann, Mostardeiro \& Cia, José Mena, Nicolau Kholer \& Filhos, Otero,Filhos \& Cia, Luchsinger \&Cia, Archer \& Luce, Antonio Francisco de Castro, Casa Brutschcke, João Carlos Reiniger \& Cia, Filtscher, Bastian \& Cia, Dreher \& Reuter y Meyer $\&$ Cia. (FORTINI, 1966, p.25).

Outra rua importante, em termos econômicos, era a General Câmara. Foi a primeira rua a receber calçamento e, devido à sua centralidade, muitas foram as empresas que nela se instalaram. Os bancos Française et Italiane Pour Amérique du Sur (instalado em 1917), o British Bank of South America (instalado em 1863) alugaram prédios nessa rua. O Banco do Brasil, instalado na cidade em 1916, escolhe para sua sede administrativa um edifício localizado bem na esquina com a Rua 7 de Setembro. Além das sedes bancárias, outras empresas como a Companhia União Telefônica se instalaram nessa rua, esquina com a Rua Riachuelo.

Neste sentido, a rua passa a ser símbolo de modernidade, de oportunidades culturais, mas, com as transformações urbanas que estavam se produzindo, ela era também sinônimo de oportunidades de investimentos de capitais. Uma rua que merece destaque, não por ser uma rua comercial mas por ser uma das primeiras ruas onde se localizaram os prédios públicos da cidade e, conseqüentemente, as famílias mas ricas, era a Rua Duque de Caxias. Roche (1966) e Geiger (1963), ao estudarem a cidade de Porto Alegre, vislumbraram a riqueza da mesma pois nessa rua localizada na crista da península, estavam localizadas as repartições públicas, palácios e monumentos. Ter um imóvel ou um comércio em determinadas ruas era ter um capital circulante e o valor do solo era alto com relação a outras áreas da cidade.

A Rua Duque de Caxias possuía três praças - a da Matriz, a Conde de Porto Alegre e a General Osório. Em 1892 havia nesta rua 317 prédios, sendo 35 sobrados e 40 assobradados. Nela estavam as casas apalacetadas do Visconde de São Leopoldo e das famílias aristocráticas da cidade; como era o caso dos Barreto Pereira Pinto, dos Corrêa Câmara, entre outros (FRANCO,1998, p.140). Com a abertura de uma grande avenida e com a remodelação do espaço urbano, os terrenos se valorizavam, particularmente aqueles situadoa nas zonas nobres da cidade, onde as elites fixavam suas residências. Cabe recordar que, mesmo com a expansão da cidade, essa rua não seria ameaçada e sim valorizada (VILLAÇA, 1992, p.204).

\section{As transformações no espaço urbano}

Pensar a cidade, principalmente no início do século $X X$, é refletir e analisar o modo de vida da mesma e a forma como os agentes econômicos e políticos interferiam no espaço 
urbano. O desenvolvimento comercial e industrial da cidade proporcionou a criação e remodelação de novos espaços. Pesavento (1995) analisa que devemos entender que o espaço construído, ordenado e transformado pela destruição dos becos, a abertura das avenidas, a construção de viadutos suscita sensações, percepções e a elaboração de representações para aqueles que vivenciavam o processo de mudança na cidade.

Do ponto de vista urbanístico, o modelo territorial estava baseado na corrente progressista, em moda por parte de urbanistas e planejadores de todo o mundo. Seus princípios eram, entre outros, transformar a cidade em um espaço funcional onde o viver, o trabalhar, o recrear-se e o circular deveriam estar presentes em todos os planos de ordenação. Condenavam a rua antiga porque a mesma simbolizava a desordem, e a questão de higiene deveria estar vinculada à circulação. Neste momento, as referências estéticas serão geométricas e ortogonais (CHOAY, 1992).

Com o aumento da população e com o rápido crescimento comercial e industrial da cidade de Porto Alegre na virada do século $X X$ até os anos 1920, a remodelação dos espaços urbanos era uma necessidade. Mesmo com a implantação das inovações tecnológicas e das redes técnicas - que beneficiavam uma pequena parte da população da cidade- esta passava por uma crise energética, a água que abastecia a população era de péssima qualidade e, mesmo na área central da cidade, havia lugares que não eram servidos pelas redes de esgotos. As ruas centrais, especialmente as mais movimentadas estavam em péssimas condições (MONTEIRO,1995). Neste sentido, os agentes locais (principalmente comerciantes e industriais) reivindicavam e solicitavam um plano de remodelação urbana. Os processos de apropriação do espaço identificavam-se com os mecanismos adotados pela nova classe emergente (os imigrantes burgueses), que vão exigir uma transformação e uma produção do espaço de acordo com seus interesses.
Em 1914, ainda na gestão de José Montaury (1897-1924), realizou-se um Plano Geral de Melhoramentos e Embelezamentos da Capital, que buscava abrir novas avenidas e alargar as antigas ruas do centro da cidade. Além disso contemplava integrar o núcleo comercial, financeiro e administrativo ao futuro porto, ordenando os terrenos ganhos ao longo das margens dos rios, conectando o porto à Estação Férrea e, também, ligando o centro aos bairros mais afastados. O eixo principal do plano era a reorganização do espaço central da cidade com relação à construção do porto novo, fazendo-o comunicar-se com a zona comercial da cidade e permitindo melhor circulação de mercadorias, veículos e pessoas. Tal plano previa a abertura de duas grandes avenidas (a avenida do Porto e a Júlio de Castilhos), paralelas ao novo cais do porto, e o alargamento das ruas perpendiculares ao porto (Relatório Intendência, reimpresso em 1927).

A cidade adota um novo modelo tecnológico e social vinculado ao instrumento territorial (os planos de ordenação), mais adequado para o desenvolvimento das novas forças produtivas que vão exigir e colocar em andamento os novos programas de transformações urbanísticas, produzindo um fenômeno de construção, de destruição e de reconstrução do espaço urbano, cujos objetivos são os de dar e/ou acomodar os novos objetivos de rentabilidade econômica através da valorização do solo urbano (ESTÉBANEZ ALVAREZ, 1991). A construção de novas avenidas desafogaria o tráfego da Rua Voluntários da Pátria e promoveria a valorização das áreas aterradas. Anos depois, analisando - sítio urbano da cidade de Porto Alegre, AB'Sáber (1966, p.20) disse que as únicas modificações ponderáveis e suficientes para um certo desafogo da circulação interna na parte central da cidade foram os aterros efetuados entre a Rua da Praia e o cais do Porto, assim como a abertura da larga avenida Borges de Medeiros que interligava os dois flancos do promontório através de um traçado em enseladura artificial. 
Infelizmente o Plano Geral de Melhoramentos e Embelezamentos da Capital não saiu do papel, e em 1924 o governo de Otávio Rocha, preocupado com a mobilidade e circulação das pessoas, realizou a abertura das avenidas Júlio de Castilhos, Borges de Medeiros e a ampliação da rua São Raphael, além das reformas referentes aos serviços urbanos. Segundo Bakos (1996, p.101): “planeja-se abrir largas avenidas, promovendo a cidade com espaços livres para o lazer, criar bom sistema de viação urbana para prevenir a superpopulação em determinados pontos, arborizar as vias públicas e promover a remoção constante de detritos".

É evidente que, se olharmos desde o ponto de vista do urbanismo, as ruas regulamentadas representam um notável progresso, pois têm uma coerência de tipo formal, os espaços abertos são generosos e estão dispostos de maneira flexível (HALL, 1996, p.67). A preocupação em remodelar o espaço urbano era uma das exigências sociais, higiênicas e estéticas promovidas pela elite local, uma vez que os discursos impunham a necessidade de ser e parecer moderno. Com as novas transformações urbanas, estas seriam contempladas com a valorização de seus comércios, residências e indústrias e serviam de referência à elite local como padrão e conceito de cidade moderna.

As facilidades das comunicações: a abertura das grandes avenidas

Se circular era um dos objetivos da corrente progressista, para isso era necessário construir amplas e retas avenidas para facilitar as comunicações e o acesso ao núcleo urbano, onde estavam concentrados os capitais comerciais e financeiros da cidade, além do poder político.

Neste sentido, os mecanismos de transformação desenvolvidos numa sociedade capitalista fazem com que as reformas das estruturas produtivas apareçam com novas relações de produção e um sistema de propriedade, que vão originar-se nas transformações espaciais da cidade. Estas podem modificar todo o tecido urbano herdado, levando as elites locais a uma série de estratégias no processo de construção, de destruição e reconstrução desses espaços. Portanto, a facilidade das comunicações requeria ruas retas e amplas, com alienações regulares, cruzamentos amplamente dimensionados e que recortem boa parte do espaço urbano. Construir largas avenidas era redimensionar o espaço urbano e fazer com que as pessoas circulassem com mais facilidade.

Mas percebemos que os inúmeros discursos produzidos pelos intendentes da cidade de Porto Alegre retratam como a construção, a destruição e a reconstrução desses espaços tinha um cunho extremamente moralista, uma vez que os becos, os indesejados e as pessoas de baixo poder aquisitivo seriam removidos dessas ruas. Pesavento (1995) assinala que, sem dúvida, estas vivências eram testadas frente ao consumo de padrões de referência já estabelecidos: as largas avenidas, os viadutos ou o saneamento urbano, com a "varrida dos pobres" do centro da cidade, eram práticas sociais ligadas ao conceito da cidade moderna e da civilização.

Exigências morais, higiênicas e estéticas imperiosas se impunham diante da necessidade de "ser" e "parecer" moderno. Mesmo que o processo de renovação urbana em curso não se aproximasse, em termos de escala, do das metrópoles reais que suportavam o conceito, a população afetada pelas demolições vivenciava a situação como pertinente ao acesso à modernidade. Em suma, os porto-alegrenses sentiam a sua cidade como metrópole e a representavam como tal em crônicas de jornais, poesias, imagens e discursos variados (PESAVENTO, 1994). Por exemplo, o jornal Diário de Notícias, publicado em 2 de julho de 1925, no artigo intitulado A cidade, dizia: “ sendo Porto Alegre, a quarta ou quinta cidade 
do Brasil em população, e uma das primeiras em importância comercial e industrial, há, aqui, entretanto, hábitos e costumes que nada a elevam no conceito de uma cidade realmente civilizada".

Em definitivo, se tratava de apropriarse de um patrimônio existente (com inúmeros problemas sociais) para construir e/ou reconstruir uma nova cidade. A hausmanização da cidade de Porto Alegre (inspirada no modelo adotado por Haussman -1853/1871- de remodelação de Paris) consistia em transformar a cidade com ruas e avenidas largas e retas, o que facilitaria não somente a "ocultação da miséria", mas, também, a melhor mobilidade das pessoas, dos carros e de mercadorias.

\section{Avenida Júlio de Castilhos}

Avenida localizada na área central da cidade de Porto Alegre, que faz parte da área conquistada do Guaíba na década de 1920. Iniciou-se, nesta época, a primeira grande reformulação do governo de Otávio Rocha (1924-1928), que introduziu as infra-estruturas necessárias na cidade. Nesse processo de construção, de destruição e de reconstrução do espaço urbano a primeira medida foi a abertura da avenida Júlio de Castilhos. Tal avenida possibilitaria a reorganização do espaço central da cidade e atendia à preocupação da elite porto-alegrense com relação ao saneamento e a estética da cidade, necessária para o grande comércio. A rua Voluntários da Pátria sofria um saturamento com relação ao trânsito e, por este motivo, encontrava-se em péssimas condições. Em 1925, no relatório do Intendente Otávio Rocha, o mesmo dizia que: "a Rua Voluntários da Pátria é insuficiente para o seu intenso tráfego e nem sequer é possível mais conservarse o seu calçamento, quanto mais remodelá-lo, pelo perigo do congestionamento e conseqüente paralisação do comércio em grosso ali localizado. Está às vistas de todo mundo este fato. Foi preciso pensar em solucionar o caso e o único meio encontrado foi ativar a execução de uma obra importante, já prevista desde
1914, a Avenida Julio de Castilhos. Esta avenida terá seu ponto inicial nos fundos do Mercado e terminará na estação da Viação Férrea. Descongestionará de fato o tráfego da Rua Voluntários da Pátria, como mais tarde a Avenida do Porto deve descongestionar esta última $(\ldots)$. Pus mãos às obras e iniciei as desapropriações para levá-la a efeito" .

Com a abertura da avenida Julio de Castilhos o comércio seria beneficiado, pois conectava rapidamente o porto com a Estação da Viação Férrea. Recordamos que nessa área estavam localizadas as casas comerciais que trabalhavam com produtos de importação e exportação, ou seja, comércios vinculados a exportar produtos da zona colonial e importar produtos manufaturados do centro do país e do exterior (MONTEIRO, 1995, p.94). Essa reforma urbana assegurava, segundo os agentes políticos, o crescimento econômico e financeiro da cidade de Porto Alegre.

\section{Avenida Borges de Medeiros}

Outra grande avenida construída neste período foi a Borges de Medeiros. Os discursos eram carregados de significados, percepções e sensações por parte da elite porto-alegrense que exigia uma cidade moderna e sem "problemas sociais". A construção da avenida Borges de Medeiros legitimaria os anseios da elite porto-alegrense, uma vez que destruiria velhas casas localizadas nos antigos becos da cidade. Sabemos que as grandes avenidas vão se configurar nas cidades segundo as necessidades funcionais e simbólicas da elite. As pequenas ruas, os becos, as ruas tortuosas e estreitas vão sendo transformadas pouco a pouco. Os jornais da época retratavam com entusiasmo as novas transformações urbanas, O jornal a Federação de 8 de agosto de 1925, publicou a seguinte notícia: “já começou a demolir velhas casas da zona central, rasgando de lado a lado da cidade umas magníficas avenidas que bastarão amplamente ao escoamento normal de veículos" (MONTEIRO, 1995). Outra vantagem da nova avenida era a 
conexão direta e rápida do centro da cidade com os bairros mas afastados, uma vez que os bondes poderiam circular sem a necessidade de fazer um percurso maior e contornar a colina central.

No Relatório da Intendência de 1925, Otávio Rocha escreveu o seguinte: “julguei que a obra era apenas de higiene e de embelezamento da cidade e não uma obra de viação. Com a largura de 13 metros. Sem ligação com o Porto, em nada viria melhorar o tráfego de veículos e muito menos concorrer para descongestionar a circulação dos bondes (...). As rampas de acesso à rua Duque de Caxias, que atualmente tem $9 \%$ e $12 \%$ ficarão reduzidas, respectivamente, de $1 \%$ a $5 \%$ para o que se vai fazer o rebaixamento de 13 metros no ponto culminante. Aí será construído um viaduto de cimento armado, em arco abatido, por onde se fará a passagem da rua Duque de Caxias (... ) Nessa avenida, que terá 21 metros de largura e 1.050 metros de extensão, vai correr uma linha dupla de bondes, em comunicação com a Avenida do Porto, separadas por abrigos centrais, por onde se hão de estender os postes de iluminação e arborização. É uma obra de viação de grande relevo porque vai encurtar o trajeto para todas as linhas de comunicação dos arrabaldes Menino Deus, Glória, Teresópolis e Partenon".

Em 1927 publica no Relatório da Intendência que a Avenida Borges de Medeiros era uma obra de higiene e estética pela sua beleza e alto interesse para o tráfego, para o qual se haviam demolido 81 prédios entre a ruas
Riachuelo e Coronel Genuíno. Salientava que: "é claro que nunca pensei em concluir tal obra, mesmo porque não a incluí no programa da administração. Sou apenas um iniciador..."

Essa série de construção-destruição e reconstrução das Avenidas Júlio de Castilhos e Borges de Medeiros vai promover as transformações no espaço urbano. Segundo Monteiro (1995, p.102), os argumentos estéticos, higiênicos e funcionais transferem-se, assim, do meio físico para o meio político social. A elite porto-alegrense pautará as novas relações sociais sempre relacionando as transformações urbanas aos desejos de moralização das classes mais pobres. Podemos perceber que a mesma esteve sempre aliada a autoridades locais, criando a figura de um novo cidadão asseado, bem vestido e adepto da moral burguesa, ou seja, um cidadão elitista e que busca no discurso da modernidade e da modernização do espaço urbano seus anseios, percepções e sensações de uma cidade limpa, higiênica e acima de tudo moral.

Portanto, a elite da cidade de Porto Alegre, enriquecida por uma economia comercial e industrial, foi a que mais investiu e se mobilizou para que fossem implantadas todas as redes técnicas, promovendo as transformações urbanas, construindo novos espaços, destruindo os espaços indesejados e reconstruindo uma nova cidade. Esta pensada, idealizada, ordenada e projetada para ser um lugar de conduta civilizada, enfim criar e transformar a cidade dos sonhos em uma cidade ideal.

\section{Bibliografia}

AB'SABER, A. N. e ROCHE, J.: Três estudos RioGrandenses. Porto Alegre: Editora UFRGS, 1966.

AB'SABER,A.N. O sítio urbano de Porto Alegre. In: AB'SABER,A.N. e ROCHE, J: Três estudos RioGrandenses. Porto Alegre: Editora UFRGS, 1966, pp. 9- 27.
BAKOS, M.M. Porto Alegre e seus eternos intendentes. Porto Alegre: EDIPUCRS, 1996.

BERTRAND, M-J. La ciudad cotidiana. Madrid: Instituto de Estudios de la Administración Local, 1981.

CHOAY,F. O Urbanismo. São Paulo: Editora Perspectiva. 1992. 
ESTÉbANEZ ALVARES,J. Las ciudades. Morfología $y$ estructura. Madrid: Sintesis.1991.

FORTINI, A. História da nossa história. Porto Alegre. Porto Alegre: Editora Grafipel, 1966.

FRANCO, S. da C. Porto Alegre - Guia Histórico. Porto Alegre: Editora da Universidade/ UFRGS, 1998.

GEIGER,P.P. Evolução da rede urbana brasileira. Rio de Janeiro: Instituto Nacional de Estudos Pedagógicos/MEC, 1963.

GOURDON, J-L. Rue/voie spécialisée: formas urbaines en opposition. Espaces et Sociétés. Paris: L'Harmattan, no. 96,1999, pp. 51-66.

HALL, P. Ciudades del mañana. Barcelona: Ediciones de Serbal.(1996:67)

LANGemanN, E. O Banco Pelotense \& O Sistema Financeiro Regional. Porto Alegre: Mercado Aberto, 1985.

LEFEBVRE, H. De lo rural a lo urbano. Barcelona: Ediciones Península, 1971.

MONTEIRO, C. Porto Alegre: urbanização e modernidade. A construção social do espaço urbano. Porto Alegre: Editora PUC/RS, 1995.

PESAVENTO, S.J. Muito além do espaço: por uma história cultural do urbano. Estudos Históricos. Rio de Janeiro, vol.8, n.16, 1995, pp. 279-290.
PESAVENTO, S.J. Um novo olhar sobre a cidade: a nova história cultural e as representações do urbano. In: Porto Alegre na virada do século 19: cultura e sociedade. Porto Alegre:UFRGS/ULBRA/ UNISINOS, 1994.

ROCHE,J. Porto Alegre, Metrópole do Brasil Meridional. In: AB'SABER,A.N. e ROCHE, J: Três estudos Rio-Grandenses. Porto Alegre: Editora UFRGS, 1966, pp. 67-86.

UEDA, V. Innovación tecnológica y cambio social: agentes y estratégias en las redes de telecomunicaciones en Rio Grande do Sul (18521930). Universidad de Barcelona: Tese Doutoral, 2002.

UEDA, V. Modernización y difusión de la telefonía en las ciudades de Porto Alegre y Pelotas (18821908). Estudos Ibero-Americanos, PUCRS, v. XXVII, no. 1, 2001, pp.159-172.

VELHO,G. Estilo de vida urbana e modernidade. Estudos históricos. Rio de Janeiro, vol. 8 no. 16, 1999, pp. 227-234.

VILLAÇA,F. Espaço intra-urbano no Brasil. São Paulo: Nobel, 1998.

Diário de Notícias - 2 de julho de 1925.

Relatório Intendência de Porto Alegre. Gestão do Prefeito Otávio Rocha. Porto Alegre: Livraria do Globo, 1925 e reimpresso em 1927. 
